\title{
Flexible learning support in an inflexible society
}

\author{
Lee Griffiths \\ School of Computing, Science and Engineering, \\ University of Salford, \\ Manchester, United Kingdom, \\ 1.s.griffiths@salford.ac.uk
}

\begin{abstract}
In this paper the author describes an approach to improving staff-student communications in order to better support full-time students in Higher Education. The paper proposes that a suitable method to support modern learners might be to adopt a blended approach to post lecture support using technology to promote staff student interaction on an individual basis. To this end a qualitative trial was conducted to test the concept. The trial had three main practical objectives; 1) to investigate document sharing tools for use in Higher Education; 2) to use such tools to enable an individual and accountable dialogue with students and 3) to examine whether improving dialog was seen as a positive improvement to quality in teaching. The results of the work indicate that the relationship with students is improved when communication is individually focused and that students can better manage their academic workload, but at the same time raises issues around staff workload and practices.
\end{abstract}

Keywords- Collaborative working; GoogleDocs; blended learning; flexibile learning; asynchronous learing; cloud computing

\section{INTRODUCTION}

Poor attendance and engagement in Higher Education (HE) is a complex problem with students describing their attitudes towards timetabled events in extreme ways from "I never miss them" to "they're worthless," [3] and it is widely accepted that there is a correlation between poor attendance and performance in HE. For example Burd and Hodgson's [1] five year study of attendance and final degree award showed a strong correlation between significantly reduced performance and an acceptable drop in attendance based on Colby's $80 \%$ rule [4].

The current climate in the UK and regulations imposed by the Higher Education Funding Council for England (HEFCE) mean that poor performance and high attrition rates have a significant negative economic impact on institutions. It may also mean that students become more demanding in the future, expecting a level of service not currently offered. Universities will face tougher times as noted by Britain's Universities minister David Willets, with universities "needing to find cheaper and more flexible ways to teach" [11]. It is also acknowledged however that attrition can be reduced by improving the staff-student relationship and taking into account individual learning styles and situations. The result of this can be an improvement in engagement and ultimately performance [1]. However, it does not always follow that adding more classes improves engagement and can be financially prohibitive.

Students lead lives which are busier than perhaps many teaching staff are aware of and the only way they can accommodate their activities is to hope for some flexibility in parts of their timetable. Given that most programmes contain 600 indicative learning hours over typically 12 weeks, students are expected to spend around 50 hours per week on their academic work. This if taken literally could mean working five fulltime days at 10 hours per day and it is likely that some activities have to suffer in order for them to manage this workload. It is no surprise to see this elsewhere in the world with Australian students also finding it "Difficult to balance study and work commitments" being cited as the second highest reason for attrition [8].

\section{A WAY FORWARD}

Using technology to ease the academic relationship in order to improve engagement may be one way of addressing these problems. Offering a near on-demand support system local to a module removes the necessity and reliance on timetabled physical sessions and adds infinitely more flexibility to student support. This could also allow the academic to engage in other activities more efficiently such as research or supporting other modules in a similar fashion.

Perhaps the most ideal technical solution to deliver learning support flexibly this way would provide a service that was simple, ubiquitous but most importantly offer a way to communicate with a student directly over a piece of work - mimicking a traditional classroom approach with regard to the academic work but suiting the students' "net generation" approach of always online. The solution would be specifically required to allow the lecturer to browse student work as it is developed by them and offer feedback directly into it, indicating where improvements need to be made or to acknowledge good progress.

\section{POSSIBLE TECHNICAL SOLUTIONS}

There are several technical solutions which allow rich communication with students. These range from open source, free services through to commercial or enterprise systems and some of the most popular solutions are briefly reviewed in sections $A$. to $D$. below. 
In terms of one-to-one communications all institutions have email, but experience suggests that supporting students by reviewing their work this way can be an inefficient process. A typical scenario might be that a student sends the academic a piece of work written in Microsoft Word. The academic reads the email, downloads the document and opens it to review the work and adds comments to it. This then has to be saved and attached to a reply email to the student. When supporting large classes this way the process is awkward, inefficient and increases physical computer usage.

\section{A. Virtual Learning Environments}

Virtual Learning Environments (VLEs) are typically employed by universities to provide wholesale support to students. Blackboard (www.blackboard.com) is the proprietary VLE chosen by Salford to support students. It contains all the tools you would expect from a typical VLE including discussion boards, blogs and wikis, but they are poor in comparison to many freely available collaborative tools and are module centric, making it difficult to have a dialog with an individual student. Despite these limitations, Blackboard is a significant provider claiming over 5000 customers worldwide, but anecdotally losing market share to open source platforms such as Moodle.

\section{B. Sharepoint, Office Live and Office 365}

SharePoint is Microsoft's solution for collaborative working in an enterprise setting. It allows users to collaborate, treating the system as a document repository with features such as browser based editing of documents. It is perhaps more suited to supporting a business infrastructure than education and as of 2011 does not currently facilitate live editing of documents with other users. However, some institutions are trialing the use of SharePoint to support their teachers and learners [10]. New from Microsoft in 2011, Office 365, promises to bring together web accessible document features of Office Live, user control of Exchange Server and collaborative control of SharePoint all in a private cloud based environment [7] and could provide stiff competition for the current main VLE environments Blackboard and Moodle.

\section{GoogleDocs}

GoogleDocs (http://docs.google.com) is a suite of webbased 'office' applications which enables storing, sharing, and editing of documents, spreadsheets, and presentations collaboratively online. They are free and several institutions in the UK already have formal agreements with Google to provide a bespoke and private cloud based service for sharing documents. You and your students' work resides within Google's domain so the security conscious may get nervous about the protection of their data. Both Blackboard and Moodle now have extensions which interface with GoogleDocs [5].

\section{GoogleWave}

GoogleWave (http://wave.google.com) is in some ways a mature version of GoogleDocs adding Twitter like messaging, conversation history tools and 3rd party extensibility amongst other features to their original document collaboration. Technologically it is the most advanced for a free service, but it is more about group collaboration so in terms of supporting a class of students is not appropriate for individual dialog or managing a large group of individual conversations in a simple way.

\section{RESEARCH METHOD}

The author delivers a second year module on Human Computer Interaction (HCI) in which the students are tasked with designing and building a software user interface. The starting point for this work involves the creation of a Hierarchical Task Analysis (HTA) diagram (similar to a family tree). If students get this first part incorrect then the rest of their work will likely reflect this, resulting in poor performance on the module. Previously the author has given feedback to students around the mid semester point to ensure that their work is progressing in the right direction and in many cases to motivate students to actually start the work. This has been a physically timetabled activity to ensure that all students had the opportunity for feedback. Unfortunately student take-up of this opportunity has always been poor and so the author's approach was to attempt to improve engagement by offering feedback in a more flexible way for the students. This involved offering all students taking the HCI module the opportunity of feedback for their HTA diagrams in two ways: 1) Students could create their diagrams using a GoogleDoc document and share the document with the module lecturer. 2) Students could create their diagrams using other tools, such as Microsoft Word.

The service available if students chose 1) was that the lecturer would be able to browse their work at a set time or several times over the semester to offer written (or drawn) feedback directly into the document indicating where improvements needed to be made or acknowledging good progress. This enabled the lecturer to maintain a continuous academic relationship with the student throughout the lifetime of the module as many students continued to develop their whole assignment using GoogleDocs and the lecturer was easily able to view their work as they progressed. The students who chose 2) would be able to gain feedback in a single face-to-face timetabled session as previously available by either printing out their work or reviewing it on a computer screen. GoogleDocs students were not prevented from gaining face-to-face feedback if they so desired in practical sessions. 


\section{A. Natural selection}

Whilst the work presented here did not set out to formally assess the effectiveness of using GoogleDocs for support, the offer of online feedback as an addition to faceto-face feedback yielded two sub-groups within the cohort taking the module by a process of natural or self selection. That is: Group A: those who engaged entirely with the lecturer through GoogleDocs; and Group B: those who simply did not take up the offer of formative feedback using Google docs or any other method.

It transpired that those students who chose to use GoogleDocs simply relinquished the face-to-face mode of feedback from that point onwards. This was an early indication that flexible online support was preferred by students taking the module. Thus once students had completed their assignments at the end of the semester, analysis of academic performance and subjective opinions was the obvious course of action to get initial impressions on the effectives of this method of providing feedback.

A sample of students taking the module completed the official university Module Evaluation Questionnaire (MEQ) which asks about various elements of the teaching and learning experience including a five-level Likert scale question specifically focusing on feedback. Question 15 reads: "15. The feedback I received from tutors on my work during this module was helpful and aided my learning" plus a supporting question box for addition comments to this question. This data was analyzed along with comments provided by the respondents.

\section{RESULTS}

A sample of 33 students completed MEQ's representing $43 \%$ of the whole module cohort and there was a clear outcome that feedback received directly into assignment work during the module using document sharing was particularly useful in improving learning. This positive feeling was further supported by statements from the MEQ respondents which in summary showed that they felt that it improved the accessibility to feedback by making the process more flexible than a traditional face-to-face approach. An analysis of student performance was also undertaken and it was found that in general the cohort performed as well as non-GoogleDocs supported groups from previous years. Whilst this was not a rigorous comparison it does indicate that performance was not notably affected by the difference in feedback mode chosen by the some students.

\section{CONCLUSIONS}

Overall the outcomes of this work were promising in terms of improving student support and their experience. Students who used GoogleDocs for feedback were able to spread their development over several review sessions and iteratively arrive at a good solution. At the same time it allowed the lecturer to manage time and student numbers more easily and the general feeling was that this was a more effective use of academic time whilst improving the quality of student attainment and engagement.

The transition to a blended approach to practical support is known to be a difficult one [12] but the hardest part to bring about is the cultural change required by $\mathrm{HE}$ staff in adopting a more fluid response to support. Student's working patterns do not always coincide with normal staff working hours resulting in a synchronicity problem. Using collaborative tools in the way described in this paper allows staff to take an asynchronous learning approach [1] to feedback so that modern learners can be supported better given their various commitments.

However, as the suggestion here is to effectively support a traditionally taught course in a distance learning way, then levels of stress in staff may increase [9] particularly if they find it difficult to communicate in a "net generation" manner.

\section{REFERENCES}

[1] Bourne, J. R. (September 1998). Net-Learning: Strategies for OnCampus and Off Campus Network-enabled Learning. JALN, 2 (2), 70-88.

[2] Burd, E. and Hodgson, B. (2006) "Attendance and Attainment: A Five Year Study", Innovation in Teaching And Learning in Information and Computer Sciences (ITALICS), 5(2).

[3] Clay, T. and Breslow, L. (2006) "Why Students Don't Attend Class", MIT Faculty Newsletter, XVIII(4) [online http://web.mit.edu/fnl/volume/184/breslow.html]

[4] Colby J., (2004) Attendance and Attainment, 5th ICS-LTSN. Annual Conference, 31 st-2nd September, University of Ulster.

[5] Google (2009) Building blocks: connecting Google Apps for Education with Blackboard - 16/7/2009, Official Google Enterprise Blog, [online -http://googleenterprise.blogspot.com/2009/07/buildingblocks-connecting-google-apps.html]

[6] Long, M., Ferrier, F., and Heagney, M. (2006). Stay, play or give away? Students continuing, changing or leaving university study in first year. [online - accessed 16/01/2010 http://www.dest.gov.au/sectors/higher_education/publications_resour ces/profiles/stay_play_giveaway.htm]

[7] Microsoft (2010) Microsoft Announces Office 365, Microsoft News Center 19th October 2010 [online - accessed 23/11/2010 http://www.microsoft.com/presspass/press/2010/oct10/1019office365.mspx]

[8] Moody, J. (2004). Distance education: Why are the attrition rates so high? The Quarterly Review of Distance Education, 5(3), 205-210.

[9] Owen, H. (2010) The Trials and Triumphs of Adapting a Tertiary face-to-face Course to Online Distance Mode, Practice and Evidence of Scholarship of Teaching and Learning in Higher Education, 5(2), 137-155.

[10] Oxford (2010) Groupware for the University Project, Oxford University Computing Services OUCS. [online - accessed 16/12/2010 http://www.oucs.ox.ac.uk/groupware]

[11] Willets, D., (2010). Universities need radical overhaul, says David Willetts, BBC news report 10 June 2010 [online - accessed 12/12/2010 http://www.bbc.co.uk/news/10278662]

[12] Schulte, M. (2010). Faculty Perceptions of Technology Distance Education Transactions: Qualitative Outcomes to Inform Teaching Practices. The Journal of Educators Online, 7(2). 